\title{
Decadal oscillation of spring rain in northern Taiwan
}

\author{
Chih-wen Hung and Huang-Hsiung Hsu \\ Department of Atmospheric Sciences, National Taiwan University, Taipei, Taiwan
}

Mong-Ming Lu

Central Weather Bureau, Taipei, Taiwan

Received 25 August 2004; revised 12 October 2004; accepted 25 October 2004; published 23 November 2004.

[1] This study found that the spring (February-April) rainfall in northern Taiwan has fluctuated concurrently with the Pacific Decadal Oscillation (PDO) since the early 20th century. It is proposed that this fluctuation in spring rain is induced by the tropical sea surface temperature (SST) anomaly embedded in the PDO, which has been known to oscillate in opposite phase to the SST in the extra-tropical North Pacific. When the PDO index is positive (negative), the SST over the tropical Central-Eastern Pacific is warmer (colder) than normal, and a low-level anti-cyclonic (cyclonic) anomalous flow is induced over the Philippine Sea. This anomalous anti-cyclonic (cyclonic) flow results in southwesterly (northeasterly) anomalous winds to the east of Taiwan and enhances (reduces) the trough extending southwestward from southern Japan to northern Taiwan. As a consequence, more (less) spring rain occurs in northern Taiwan during the positive (negative) PDO phases. INDEX TERMS: 3309 Meteorology and Atmospheric Dynamics: Climatology (1620); 3354 Meteorology and Atmospheric Dynamics: Precipitation (1854); 3339 Meteorology and Atmospheric Dynamics: Ocean/atmosphere interactions (0312, 4504). Citation: Hung, C.-w., H.-H. Hsu, and M.-M. Lu (2004), Decadal oscillation of spring rain in northern Taiwan, Geophys. Res. Lett., 31, L22206, doi:10.1029/2004GL021344.

\section{Introduction}

[2] The Pacific Decadal Oscillation (PDO) is a phenomenon characterized by sea surface temperature (SST) oscillation in the extra-tropical North Pacific [e.g., Mantua et al., 1997]. It exhibits a spatial pattern similar to that of the El Niño/La Niña, e.g., anomalies of opposite signs in the extratropical North Pacific and the equatorial Eastern Pacific, except that the PDO amplitude in the extra-tropics is larger than that in the tropics [e.g., Zhang et al., 1997]. In addition, the PDO exhibits decadal time scales, compared to the interannual time scale of the El Niño/La Niña. It was reported that the PDO changed polarity in 1925, 1947, 1977 , and possibly in the late 1990s during the 20th century [Miller et al., 1994; Mantua et al., 1997; Bond et al., 2003]. The exact mechanism for the PDO is not fully understood, although several theories have been proposed [e.g., Latif and Barnett, 1994; Deser et al., 1996; Zhang et al., 1998; Qiu, 2003].

[3] Taiwan is a subtropical island located to the southeast of China. Its annual rainfall cycle is largely influenced by the East Asian monsoon. The spring rain that occurs in the
February-April period (hereafter referred to as FMA) provides an important water resource for agricultural irrigation in northern Taiwan before the Meiyu in May and June (Figure 1a). The spring rain is significant only in northern Taiwan. The FMA season is dry in central and southern Taiwan. The frontal systems that bring spring rainfall to northern Taiwan are more active in a large-scale cyclonic environment that is often characterized by an enhanced anti-cyclonic circulation in the Philippine Sea. A weakening of this large-scale cyclonic/anti-cyclonic circulation often leads to less frontal activity and therefore less spring rainfall in northern Taiwan [Jiang et al., 2003].

[4] Using the average rainfall data for the entire Taiwan island, Lu and May [2003] showed that after 1930 the spring rain in Taiwan fluctuated coherently with the PDO. However, the reason for this linkage remains unknown. This study found that only the spring rainfall in northern Taiwan fluctuated concurrently with the PDO, modulated by the trough activity described above. The corresponding circulation and SST anomalies are examined to explore the possible PDO effect on Taiwan's spring rainfall. A possible mechanism is proposed.

\section{Data}

[5] Several independent datasets were used in this study. The monthly PDO index derived from the leading principal component of the North Pacific monthly SST (poleward of $20^{\circ} \mathrm{N}$ ) was provided by N. Mantua from the website (http:// jisao.washington.edu/pdo). The rainfall data at four Taiwanese stations (Taipei, Tamsui, An-bu, Peng-Chia Island in Figure 1b), and one Japanese station (Ishigakijima Island in Figure $1 \mathrm{~b}$ ) were used in this study.

[6] The monthly GISST 2.3b (Global Sea Ice and Sea Surface Temperature) [Rayner et al., 1996] was used to demonstrate the spatial pattern of the PDO. The sea level pressure (SLP) from the Comprehensive Ocean-Atmosphere Data Set (COADS) provided by the NOAA-CIRES Climate Diagnostics Center was used to illustrate the corresponding circulation pattern. Several variables from the European Centre for Medium-Range Weather Forecast Re-Analysis 40 (ERA40) were also analyzed for the recent PDO phase changes occurring in late 1970s.

\section{Decadal Oscillation in Spring Rainfall and Its Association With the PDO}

[7] The rainfall annual cycle in northern Taiwan can be divided into several periods: a winter dry season, spring rain, Meiyu and summer rain season. The Taipei annual 

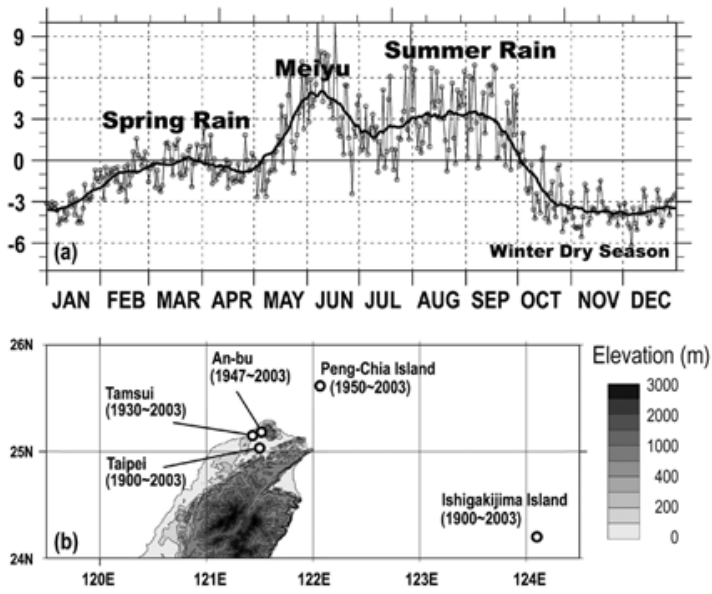

Figure 1. (a) The annual cycle of rainfalls in Taipei. (b) The locations and available data lengths of five stations used in this study.

rainfall cycle is shown in Figure 1a. The year-to-year variation in the FMA rainfall in Taipei exhibits a decadal oscillation, which can be seen clearly in the 21-year running means (Figure 2a). A similar oscillation can also be observed in other four stations (Figure 2b). A comparison to the PDO index indicates that the decadal oscillation described above fluctuated concurrently with the PDO index. The correlation coefficients between the 21-year running means of the FMA PDO index and that of the FMA rainfalls at the five stations for the available periods were $0.86,0.93$, 0.93, 0.78 and 0.65 for Taipei, An-bu, Tamsui, Peng-Chia Island and Ishigakijima Island, respectively.

[8] Since the decadal oscillation in the spring rainfall in northern Taiwan changed signs almost simultaneously with the PDO, the three PDO phase-changing years (i.e., 1925, 1947, and 1977) were used as reference years to investigate the shifts in SST and SLP before and after these turning points. The 21-year means before and after the turning years were calculated and the differences between them were computed. The 21-year length was selected, because a positive or negative phase in the PDO usually persists for 20 to 30 years.

[9] Figure 3a shows the after-minus-before (1978-97 minus 1958-77) composite for the FMA SST for the 1977 phase change. The pattern is such that the SSTs were lower in the extra-tropical western and central North Pacific and higher in other parts of the Pacific for the period after the change in the PDO. Figures $3 \mathrm{~b}$ and $3 \mathrm{c}$ present the SST patterns for the 1947 and 1925 phase changes, respectively. Both the 1947 and 1925 cases exhibit a pattern similar to that for the 1977 case, except that the 1947 case exhibits an opposite phase. These results clearly demonstrate the characteristics of the PDO, characterized by both the tropical and extra-tropical SST changes, although the patterns in central equatorial Pacific are not exactly the same.

[10] The corresponding decadal SLP changes were calculated in the same manner. The after-minus-before SLP, derived from ERA40, showed that for the change in the PDO at 1977 the SLP in the Philippine Sea were higher following the change than they were prior to that (Figure 4a). In a region that extends southwest from southern Japan to northern Taiwan, the SLP was lower following the 1977 change. In addition, the SLP became lower in the extra-tropical North Pacific north of $30^{\circ} \mathrm{N}$ and the tropical Southeastern Pacific after the change of the $\mathrm{PDO}$ at 1977. The $925 \mathrm{hPa}$ wind field from ERA40 exhibits a similar circulation pattern (Figure $4 b$ ): an enhanced trough and anti-cyclone over northern Taiwan and the Philippine Sea, respectively. The corresponding feature is enhancement of the southerly winds originating from the South China Sea after 1977.

[11] Since the ERA40 data are only available after 1958, it is not possible to perform a similar analysis for both the 1925 and 1947 cases. The COADS SLP has a longer record than the ERA40, so the same after-minus-before analysis is applied for all three cases (not shown). The results indicate that the COADS SLP patterns in the North Pacific and the extra-tropical western Pacific for the three cases are similar to Figure 4a, except that the 1947 case has an opposite phase. Because COADS data contains missing values at certain grid points, especially in the tropical regions during the first half of the 20th century, only part of the tropical pattern can be seen by this method in 1925 and 1947 cases.

[12] A correlation method based on the COADS SLP is provided, on the other hand, to obtain useful information concerning the relationship between the large-scale circulation and the spring rainfall. Figure $4 \mathrm{c}$ presents the correlation coefficients between the FMA rainfall in Taipei and the available COADS SLP. Similar results were obtained using rainfall data at other stations. The FMA rainfall in northern Taiwan is negatively correlated with the SLP anomalies in the following regions: the North Pacific north of $20^{\circ} \mathrm{N}$, the East China Sea from southern Japan to northern Taiwan, and the tropical Southeastern Pacific south of the equator. Conversely, it is positively correlated with the SLP anomalies in the Philippine Sea. The pattern shown in Figure 4c is consistent with the composite shown in Figure 4a. This

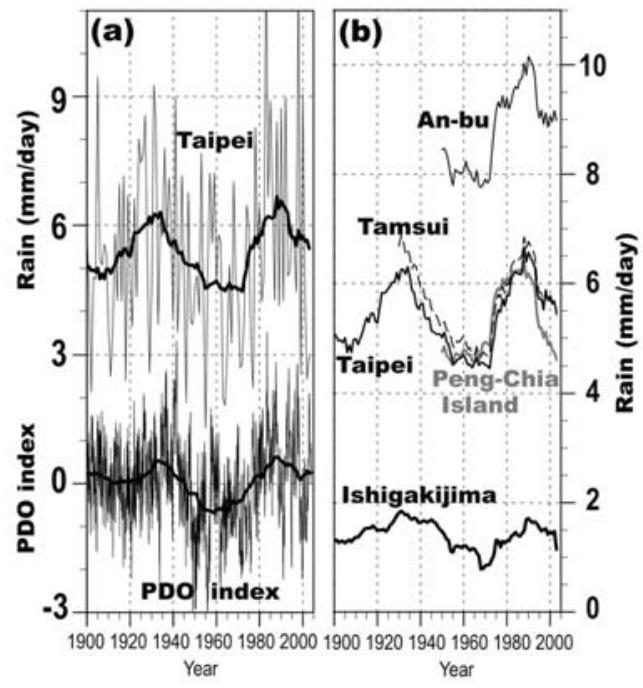

Figure 2. (a) The monthly standardized PDO index and the year-to-year variation of the FMA rainfall in Taipei. The thick line is the 21-year running mean. (b) The 21-year running means of the FMA rainfalls at 4 Taiwanese stations and 1 Japanese island (Ishigakijima). 
(a) 7897-5877

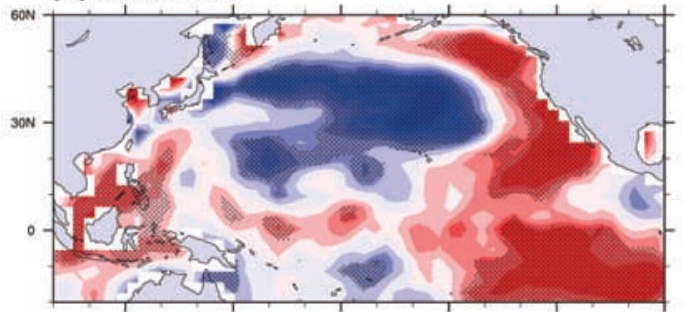

(b) $4867-2847$

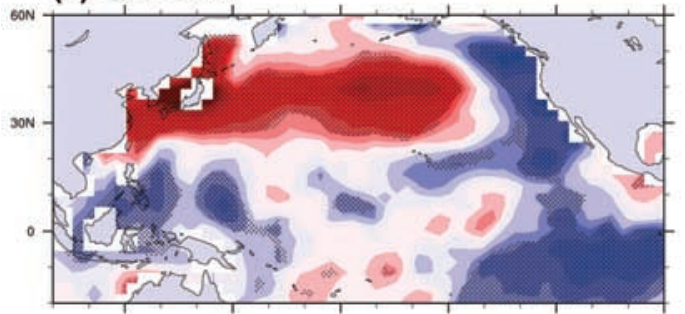

(c) 2645-0625

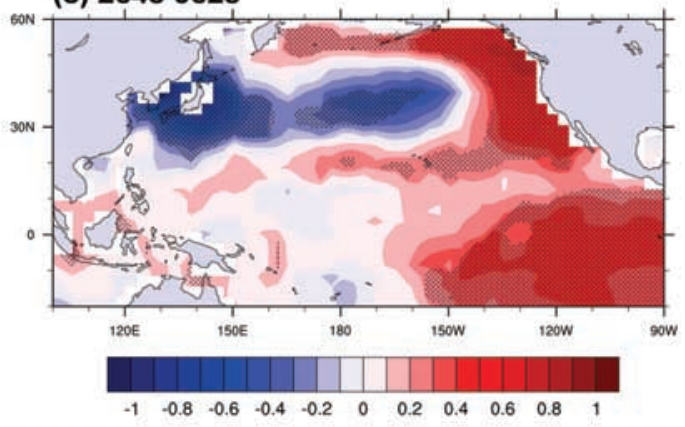

Figure 3. Differences between the 21-year mean FMA SST after and before (a) 1977 (1978-97 minus 1958-77), (b) 1947 (1948-1967 minus 1928-47), and (c) 1925 (1926-45 minus 1906-25). The t-statistic was computed and the $5 \%$ level was stippled.

indicates that the circulation pattern associated with the PDO is also the pattern that affects the FMA rainfall in northern Taiwan.

\section{Conclusions and Discussion}

[13] This study demonstrated that decadal fluctuation in the spring rainfall in northern Taiwan occurred concurrently with the PDO. More (less) rainfall springs were characterized by an enhancement (weakening) in the cyclonic/anti-cyclonic circulation pair over the East Asian margin seas and the Philippine Sea. The following discussion provides a possible mechanism to explain the PDO effect on this regional phenomenon.

[14] It has been well-known by Taiwanese long-range weather forecasters that the spring rain in northern Taiwan is positively correlated with the Nino 3.4 index, i.e., more rainfall following the El Niño peak phase and less rainfall following the La Niña peak phase [Jiang et al., 2003]. It is also interesting that the decadal oscillation patterns in the SST and SLP in the Pacific are similar to the patterns when the El Niño/La Niña occurred [Zhang et al., 1997; Wang and Zhang, 2002]. The particular circulations affecting northern Taiwan are the negative and positive SLP anomalies in the East Asian coast and the Philippine
Sea, respectively. It has been found that the same cyclonic/ anti-cyclonic anomalous flow had a great impact on the East Asian winter and summer monsoon during El Niño years [Chang et al., 2000a, 2000b; Wang et al., 2000; Hsu et al., 2001]. This anomalous circulation, which can be explained as the Rossby wave response to the SST anomaly in the equatorial Eastern Pacific, once forced can maintain itself for several seasons from winter to summer through local ocean-atmosphere interactions in the Philippine Sea and the continental shelf region [e.g., Lau and Nath, 2000; Wang et al., 2000; Hsu et al., 2001; Wang and Zhang, 2002; Lau and Nath, 2003; Chou, 2004]. Conversely, an anomalous cyclonic circulation occurring in La Niña can maintain itself through the same process. It is likely that the SST anomaly effect on the atmospheric circulation during the El Niño/ La Niña also occurs in the PDO, although the time scales are different.

[15] In the PDO, the SST over the tropical CentralEastern Pacific fluctuates concurrently but in an opposite sign with the SST in the extra-tropical North Pacific. This tropical SST variation could induce a low-level anomalous anti-cyclonic (cyclonic) circulation over the Philippine Sea to create a southwesterly (northeasterly) anomalous flow
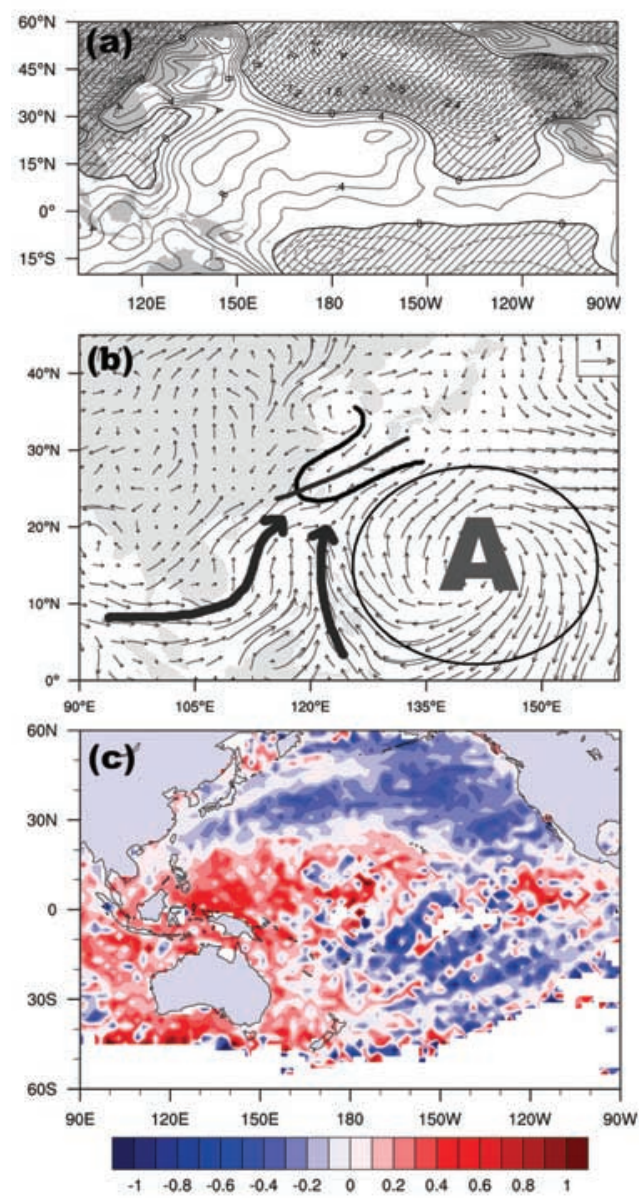

Figure 4. Same as in Figure 3 but for (a) the SLP and (b) the $925 \mathrm{hPa}$ winds $[\mathrm{m} / \mathrm{sec}]$ for the 1977 case. "A" plotted in Figure $4 \mathrm{~b}$ represents the anti-cyclonic anomaly. (c) Correlation coefficients between Taipei rainfall and the available COADS SLP in FMA. 

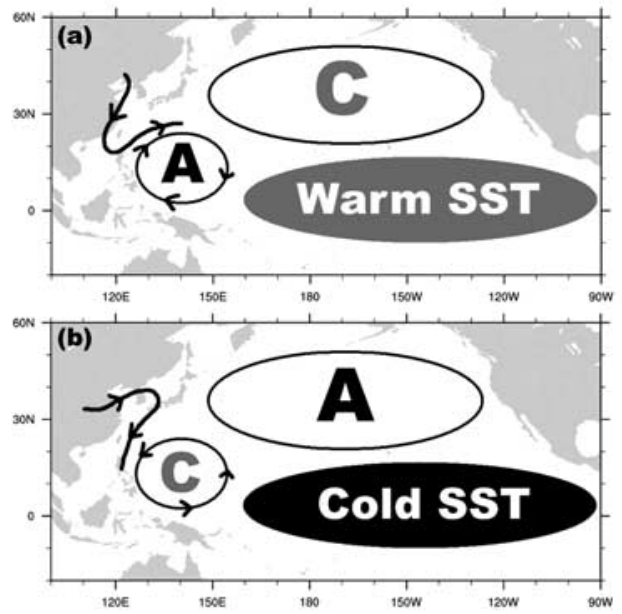

Figure 5. Schematic diagrams for the anomalous circulation in the (a) positive and (b) negative PDO phases. "A" and " $C$ " plotted in the figures represent the anti-cyclonic anomaly and cyclonic anomaly, respectively. The light (dark) gray shading area represents the warm (cold) SST anomaly.

and enhance (weaken) the trough located in the region extending southwestward from southern Japan to northern Taiwan. This effect on the trough in turn affects the spring rainfall variability in northern Taiwan.

[16] For the periods in 1925-1946 and 1977-1990s (shown in a schematic diagram Figure 5a), the PDO was in the positive phase. The SST in the extra-tropical North Pacific was lower than normal and the Aleutian low was enhanced. In the mean time, the SST over the tropical Central-Eastern Pacific was in a warm decadal phase. The mechanism described above produced an anti-cyclonic anomalous flow over the Philippine Sea, and the trough located to the northwest of Taiwan was enhanced. As a consequence, there was more spring rain in northern Taiwan. For the period of 1947-1976, an opposite situation occurred (Figure 5b). The PDO was in the negative phase, which resulted in less spring rain in northern Taiwan.

[17] Acknowledgments. The authors thank two anonymous reviewers for their useful comments on the manuscript. The computations were performed at Department of Atmospheric Sciences, National Taiwan University. This work was supported by the Central Weather Bureau under Grant MOTC-CWB-93-6M-03.

\section{References}

Bond, N. A., J. E. Overland, M. Spillane, and P. J. Stabeno (2003), Recent shifts in the state of the North Pacific, Geophys. Res. Lett., 30(23), 2183, doi:10.1029/2003GL018597.

Chang, C.-P., Y. Zhang, and T. Li (2000a), Interannual and interdecadal variations of the East Asian summer monsoon and tropical Pacific SSTs. Part I: Roles of the subtropical ridge, J. Clim., 13, 4310-4325.

Chang, C.-P., Y. Zhang, and T. Li (2000b), Interannual and interdecadal variations of the East Asian summer monsoon and tropical Pacific SSTs. Part I: Meridional structure of the monsoon, J. Clim., 13, 4326-4340.

Chou, C. (2004), Establishment of the low-level wind anomalies over the western North Pacific during ENSO development, J. Clim., 17, $2195-$ 2212.

Deser, C., M. A. Alexander, and M. S. Timlin (1996), Upper-ocean thermal variations in the north Pacific during 1970-1991, J. Clim., 9, 18401855 .

Hsu, H.-H., Y.-L. Chen, and W.-S. Kau (2001), Effects of oceanatmosphere interaction on the winter temperature in Taiwan and East Asia, Clim. Dyn., 17, 305-316.

Jiang, Z., G. T.-J. Chen, and M.-C. Wu (2003), Large-scale circulation patterns associated with heavy spring rain events over Taiwan in strong ENSO and non-ENSO years, Mon. Weather Rev., 131, 1769-1782.

Latif, M., and T. P. Barnett (1994), Causes of decadal climate variability over the North Pacific and North America, Science, 266, 634-637.

Lau, N.-C., and M. J. Nath (2000), Impact of ENSO on the variability of the Asian-Australian monsoons as simulated in GCM experiments, J. Clim., $13,4287-4309$.

Lau, N.-C., and M. J. Nath (2003), Atmosphere-ocean variations in the Indo-Pacific sector during ENSO episodes, J. Clim., 16, 3-20.

Lu, M.-M., and R.-J. May (2003), A study on the long-term variations of Taiwan and global precipitation (in Chinese), Atmos. Sci., 31, 199-220.

Mantua, N. J., S. R. Hare, Y. Zhang, J. M. Wallace, and R. C. Francis (1997), A Pacific interdecadal climate oscillation with impacts on salmon production, Bull. Am. Meteorol. Soc., 78, 1069-1079.

Miller, A. J., D. R. Cayan, T. P. Barnett, N. E. Graham, and J. M. Oberhuber (1994), The 1976-77 climate shift of the Pacific Ocean, Oceanography, 7, $21-26$.

Qiu, B. (2003), Kuroshio extension variability and forcing of the Pacific decadal oscillations: Responses and potential feedback, J. Phys. Oceanogr., 33, 2465-2482.

Rayner, N. A., E. B. Horton, D. E. Parker, C. K. Folland, and R. B. Hackett (1996), Version 2.2 of the global sea-ice and sea surface temperature dataset, 1903-1994, Clim. Res. Tech. Note 74, 43 pp., Met Off., U. K.

Wang, B., and Q. Zhang (2002), Pacific-East Asian teleconnection. Part II: How the Philippine Sea anomalous anticyclone is established during El Niño development, J. Clim., 15, 3252-3265.

Wang, B., R. Wu, and X. Fu (2000), Pacific-East Asian teleconnection: How does ENSO affect East Asian climate?, J. Clim., 13, 1517-1536.

Zhang, R.-H., L. M. Rothstein, and A. J. Busalacchi (1998), Origin of upper-ocean warming and El Niño change on decadal scales in the tropical Pacific Ocean, Nature, 391, 879-883.

Zhang, Y., J. M. Wallace, and D. S. Battisti (1997), ENSO-like interdecadal variability: 1900-93, J. Clim., 10, 1004-1020.

C.-w. Hung and H.-H. Hsu, Department of Atmospheric Sciences, National Taiwan University, No. 1, Sec. 4, Roosevelt Road, Taipei 106, Taiwan. (cwhung@webmail.as.ntu.edu.tw)

M.-M. Lu, Central Weather Bureau, Taipei, Taiwan. 